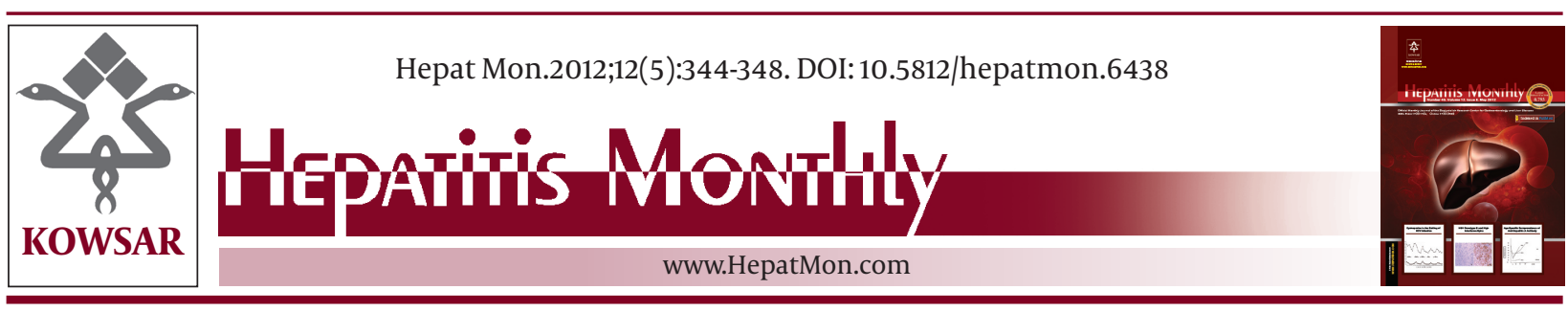

\title{
A Randomized Controlled Trial of Two Schedules of Hepatitis B Vaccination in Predialysed Chronic Renal Failure Patients
}

\author{
Farokhlagha Ahmadi ${ }^{1}$, Morteza Ramezani ${ }^{1}$, Effat Razeghi ${ }^{2}$, Neda Ranjbarnovin ${ }^{1}$, Zahra \\ Khazaeipour ${ }^{1,3^{*}}$ \\ ${ }^{1}$ Nephrology Research Center, Imam Khomeini Hospital Complex, Tehran University of Medical Sciences, Tehran, IR Iran \\ 2 Department of Nephrology, Sina Hospital, Tehran University of Medical Sciences, Tehran, IR Iran \\ ${ }^{3}$ Brain and Spinal Injury Research Center, Imam Khomeini Hospital Complex, Tehran University of Medical Sciences, Tehran, IR Iran
}

\begin{tabular}{l}
\hline A R T I C L E I N F O \\
\hline Article type: \\
Original Article \\
\hline
\end{tabular}

Article history:

Received: 23 Oct 2011

Revised: 29 Feb 2012

Accepted: 28 Mar 2012

Keywords:

Kidney Failure, Chronic

Hepatitis B

Vaccination

NCT registration identifier:

NCT01468051

\begin{abstract}
A B S T R A C T
Background: Patients with chronic renal disease should be vaccinated as soon as dialysis is forestalled, and this could improve the seroconversion of hepatitis B vaccination. objectives: In this study, we aimed to compare seroconversion and immune response rates using 4 doses of $40 \mu \mathrm{g}$ and 3 doses of $20 \mu$ g Euvax B recombinant Hepatitis B surface Antigen (HBs Ag) vaccine administered to predialysis patients with chronic kidney disease (CKD).

Patients and Methods: In an open, randomized clinical trial, we compared seroconversion rates in 51 predialysis patients with mild and moderate chronic renal failure who received either 4 doses of $40 \mu \mathrm{g}$ or 3 doses of $20 \mu \mathrm{g}$ of Euvax B recombinant hepatitis B vaccine administered at 0,1,2, 6 and 0,1, 6 months, respectively.

Results: Differences in seroconversion rates after 4 doses of $40 \mu \mathrm{g}(80.88 \%)$ compared to 3 doses of $20 \mu \mathrm{g}(92 \%)$ were not significant $(P=0.4124)$. The mean HBs antibody level after 4 doses of $40 \mu$ g at $0,1,2$, and 6 months $(182.2 \pm 286.7)$ was significantly higher than that after 3 doses of $40 \mu \mathrm{g}$ at 0,1 , and 6 months $(96.9 \pm 192.1)(P=0.004)$. Seroconversion after 4 doses of $40 \mu \mathrm{g}(80.8 \%)$ was also significantly higher than that after 3 doses of $40 \mu \mathrm{g}$ $(77 \%)(P=0.004)$. Multivariable analysis showed that none of the variables contributed to seroconversion.

Conclusions: We found that 4 doses of $40 \mu \mathrm{g}$ did not lead to significantly more seroconversion than 3 doses of $20 \mu \mathrm{g}$.

Copyright $\odot 2012$ Kowsar Corp. All rights reserved.
\end{abstract}

- Implication for health policy/practice/research/medical education:

This article presents Hepatitis B Vaccination in Patients with chronic renal disease.

- Please cite this paper as:

Ahmadi F, Ramezani M, Razeghi E, Ranjbarnovin N, Khazaeipour Z. A randomized Controlled Trial of Two Schedules of Hepatitis B Vaccination in Predialysed Chronic Renal Failure Patients. Hepat Mon. 2012;12(5):344-8. DOI: 10.5812/hepatmon.6438

* Corresponding author: Zahra Khazaeipour, Nephrology Research Center, Brain and Spinal Cord Injury Research Center, Imam Khomeini Hospital Complex, Tehran University of Medical Sciences, Tehran, IR Iran. Tel: +9866581561, Fax: +98-216693885, E-mail: z_kh14@yahoo.com; khazaeipour@ razi.tums.ac.ir

DOI:10.5812/hepatmon.6438

Copyright @2012 Kowsar Corp. All rights reserved.

\section{Background}

Chronic kidney disease (CKD) and its treatment enhance the risk of Hepatitis B Virus (HBV) infection (1). Since 1982, the $\mathrm{HBV}$ vaccine has been recommended for CKD patients and healthcare workers (2-5). Patients with CKD are immunocompromised, whether they are on dialysis or not, and have lower immune response rates (50-80\%) to the vaccine when compared with immunocompetent individuals (95\%) (6-8). Different strategies have been employed to improve 
the immune response in CKD patients, such as increasing the number of intramuscular (i.m.) doses (9), increasing the quantity of antigen in each dose (10), intradermal administration (11), and co-administration of immunogenic or immunostimulant agents such as zinc (12), levamizole (13), gammainterferon (14) interleukin-2 (15), granulocyte colony stimulating factor, and erythropoietin (16). To improve vaccination response, it is advised that CKD patients should be vaccinated as early in the course of renal disease as possible (17) using a double vaccine dose $(17,18)$ and a 4- rather than 3-dose schedule (6). Several studies in predialysis patients that have compared vaccine responses to the different doses have been inconclusive (19-21). The current vaccination strategy for predialysis patients at our centers (Imam Khomeini hospital complex and Sina hospital) is 20 $\mu \mathrm{g}(1 \mathrm{ml})$ administered at 0,1 , and 6 months. We aimed to test a new vaccination schedule because we thought the current method ineffective. In this study, we aimed to compare seroconversion rates (Hepatitis B surface Antibody [HBs Ab] $\geq 10 \mathrm{mIU} / \mathrm{ml}$ ) using 4 doses of $40 \mu \mathrm{g}$ and 3 doses of $20 \mu \mathrm{g}$ of Euvax B recombinant Hepatitis B surface Antigen (HBs Ag) vaccine administered to predialysis CKD patients.

\section{Patients and Methods}

\subsection{Sample Size}

In accordance with the McNulty et al. study (22), to perform an analysis with $80 \%$ power using a two-sided alpha level ( $\alpha=0.05)$ and assuming 66\% and 81\% seroconversion with the $20 \mu \mathrm{g}$ and $40 \mu \mathrm{g}$ hepatitis B vaccine, we needed to enroll 137 patients. All the available patients who met the inclusion criteria were recruited for this study.

\subsection{Patients}

The patients were recruited for the study from the renal outpatient clinics (Imam Khomeini hospital complex and Sina hospital) at Tehran University of Medical Sciences, which provide diagnostic and follow-up services for patients with renal disease, between October 2008 and October 2009 . Inclusion criteria were age $>18$ years, mild or moderate chronic renal failure (a serum creatinine level $=1.5-6$ $\mathrm{mg} / \mathrm{dl}$ ). Exclusion criteria were severe renal failure (a serum creatinine level $>6 \mathrm{mg} / \mathrm{dl}$ ) requiring dialysis or expected to require dialysis within 1 year, patients with positive $\mathrm{HBs} \mathrm{Ag}$, $\mathrm{HBs} \mathrm{Ab}$, or $\mathrm{HBc} \mathrm{Ab}$, patients receiving immunosuppressive treatment, and those with known lymphoproliferative disorder.

\subsection{Trial Protocol}

Records were made of demographic details, drug therapy, and the weight and height of the patients. Baseline blood samples were taken to determine the full blood count and blood chemistry, including Fasting Blood Sugar (FBS), C Reactive Protein (CRP), intact Parathyroid Hormone (iPTH), lipid profile, Albumin(Alb), Creatinin(Cr), Ferritin, and hep- atitis B and C markers. Randomization process: A 4-block randomized method was used. Patients were randomized to receive 3 doses of $20 \mu \mathrm{g}(1 \mathrm{ml})$ or 4 doses of $40 \mu \mathrm{g}(2 \mathrm{ml})$ of Euvax B vaccine (recombinant hepatitis B surface antigen adsorbed on aluminum hydroxide adjuvant; LG Life Sciences). All cases were followed until the vaccination processes were completed, and there were no withdrawals. Blinding: Blinding was not possible, because the frequency of vaccination in the two groups was unequal. The vaccine was administered (i.m.) into the deltoid muscle using a $23 \mathrm{G} \times 1$ " needle at 0,1, and 6 months (3-dose group) and at 0,1,2, and 6 months (4-dose group). Patients were followed to assess routine laboratory markers of chronic kidney disease (Glomerular filtration rate [GFR], Cr, Na, K, Ca, P, and so on) and a clinical examination was performed every 3 months. GFR was calculated using the Cockcroft-Gault formula, where GFR ml/min $=(140$-age $) \times$ weight $\times \mathrm{K} / \mathrm{Cr} \times 72$ and $\mathrm{K}=1$ (for males) or 0.85 (for females). Blood samples were taken before 6 months as well as 8-10 weeks after the 6-month dose, and were assayed for the presence of antibodies against HBs Ag (anti-HBs) using a commercial enzyme immunoassay (EIA) produced by Abbott Laboratories (AUSAB, Abbott Laboratories, Abbott Park, IL, USA).

\subsection{Hepatitis B Markers}

Hepatitis B surface antibody was determined using an anti-hepatitis B surface antibody quantitative chemiluminescence assay (EIA) produced by Abbott Laboratories (AUSAB, Abbott Laboratories, Abbott Park, IL, USA) at Noor laboratory, Tehran, Iran. Anti-HBs titers are expressed in $\mathrm{mIU} / \mathrm{ml}$ compared with standard immunoglobulin preparations (Ortho- Clinical Diagnostics). Anti-HBs titers $<10 \mathrm{mIU} / \mathrm{ml}$ were defined as non-seroconversion (non-responder). AntiHBs titers $\geq 10 \mathrm{mIU} / \mathrm{ml}$ were defined as seroconversion.

\subsection{Data Analysis}

After evaluating the normality of the data using a OneSample Kolmogorov-Smirnov Test, quantitative variables for the 2 qualitative groups were analyzed using a MannWhitney U test. The Wilcoxon Signed Ranks test was used for before and after comparisons of quantitative data. Associations between qualitative data were tested using a Chisquare test. Correlations between 2 quantitative variables were evaluated by Spearman's correlation analysis. Logistic regression analysis model was used to evaluate predictors of response to vaccination. In this model, responses to 3 doses of $20 \mu \mathrm{g}$ and 4 doses of $40 \mu \mathrm{g}$ of $\mathrm{HBs} \mathrm{Ab}(<10$ and $\geq 10$ $\mathrm{mIU} / \mathrm{ml}$ ) were dependent variables and type of vaccination, age, ferritin, FBS, HDL, Alb, weight, and HCV Ab were independent variables. Quantitative variables were presented as mean \pm standard deviation (SD). The significance level was set at $P \leq 0.005$. Ethics: Since 1996, the English National Immunization Guide (8) has recommended that "in addition to those already on hemodialysis, the immunization of all patients with chronic renal failure is recommended, 
as soon as it is anticipated they may require dialysis". An information sheet explaining the randomization process, the vaccination dose, follow-up, and the rationale for the study was provided to the patients. We obtained their written consent to participate in the study after they had read the information leaflet and discussed it with us. The study was approved by the research ethics committee of Tehran University of Medical Sciences.

\section{Results}

Of 64 predialysis patients, 51 completed the 8-month follow-up (26 patients received 4 doses of $40 \mu$ g, and 25 patients 3 doses of $20 \mu \mathrm{g}$ ). Two of the remaining patients died, 2 required dialysis, and 9 were eliminated from the study because of problems reaching Tehran from other cities. There were no significant differences in the frequency and etiology of withdrawal between the 2 groups. The patients all had stage 3 or 4 renal failure, but gender differed significantly between the 2 groups: 8 patients (32.0\%) in the 3-dose group and 18 (69.2\%) in the 4-dose group were male $(P=0.008)$. Analysis of the age, weight, serum $\mathrm{Cr}, \mathrm{Alb}, \mathrm{Hb}$, CRP, PTH, ferritin, FBS, LDL, HDL, cholesterol, and GFR of the

\begin{tabular}{|c|c|c|c|}
\hline & $20 \mu g$ - 3 Dose Group $(\mathbf{n}=25)$ & $40 \mu g$ - 4 Dose Group $(n=26)$ & Pvalue $^{b}$ \\
\hline Gender, No. & & & $0.008^{c}$ \\
\hline Male & 8 & 18 & \\
\hline Female & 17 & 8 & \\
\hline Weight, kg, mean \pm SD & $72.6 \pm 9.3$ & $69.7 \pm 6.6$ & 0.12 \\
\hline Age, $y$, mean \pm SD & $56.9 \pm 13.0$ & $57.1 \pm 11.9$ & 0.76 \\
\hline $\mathrm{GFR}^{\mathrm{a}}, \mathrm{ml} / \mathrm{min}$, mean $\pm \mathrm{SD}$ & $31.8 \pm 10.9$ & $34.9 \pm 13.9$ & 0.46 \\
\hline Albumin, $\mathrm{g} / \mathrm{dl}$, mean $\pm \mathrm{SD}$ & $4.6 \pm 0.4$ & $4.4 \pm 0.4$ & 0.10 \\
\hline Creatinine, $\mathrm{mg} / \mathrm{dl}$, mean \pm SD & $2.7 \pm 1.0$ & $2.6 \pm 0.8$ & 0.95 \\
\hline $\mathrm{Hb}^{\mathrm{a}}, \mathrm{g} / \mathrm{dl}$, mean $\pm \mathrm{SD}$ & $11.6 \pm 2.0$ & $12.3 \pm 1.9$ & 0.52 \\
\hline $\mathrm{CRP}^{\mathrm{a}}, \mathrm{mg} / \mathrm{dl}$, mean $\pm \mathrm{SD}$ & $2.9 \pm 4.4$ & $3.4 \pm 4.5$ & 0.84 \\
\hline $\mathrm{PTH}^{\mathrm{a}}, \mathrm{pmol} / \mathrm{l}$, mean $\pm \mathrm{SD}$ & $153.2 \pm 149.0$ & $103.9 \pm 78.2$ & 0.27 \\
\hline Ferritin, ng/ml, mean \pm SD & $120.0 \pm 94.6$ & $132.8 \pm 113.6$ & 0.77 \\
\hline $\mathrm{FBS}^{\mathrm{a}}, \mathrm{mg} / \mathrm{dl}$, mean $\pm \mathrm{SD}$ & $105.9 \pm 34.2$ & $111.2 \pm 34.9$ & 0.22 \\
\hline $\mathrm{LDL}^{\mathrm{a}}, \mathrm{mg} / \mathrm{dl}$, mean $\pm \mathrm{SD}$ & $100.8 \pm 30.9$ & $87.4 \pm 24.9$ & 0.10 \\
\hline $\mathrm{HDL}^{\mathrm{a}}, \mathrm{mg} / \mathrm{dl}$, mean $\pm \mathrm{SD}$ & $42.0 \pm 12.8$ & $44.9 \pm 16.3$ & 0.59 \\
\hline Cholesterol, mg/dl, mean \pm SD & $185.7 \pm 44.2$ & $170.8 \pm 39.6$ & 0.19 \\
\hline
\end{tabular}

a Abbreviations: CRP, C Reactive Protein; FBS, Fasting Blood Sugar; GFR, Glomerular filtration rate Hb, Hepatitis B; HDL, High-density lipoprotein; LDL, Low-density lipoproteinm, PTH, Parathyroid Hormone; GFR, Glomerular filtration rate

b Mann-Whitney U Test

${ }^{\mathrm{c}}$ Chi-Square Test

Table 2. Logistic Regression Analysis to Determine Predictors of Antibody Response (HBs Ab $\geq 10 \mathrm{mIU} / \mathrm{ml}$ ) After 3 Doses of $20 \mu \mathrm{g}$ and 4 Doses of $40 \mu \mathrm{g}$, HBV Vaccination

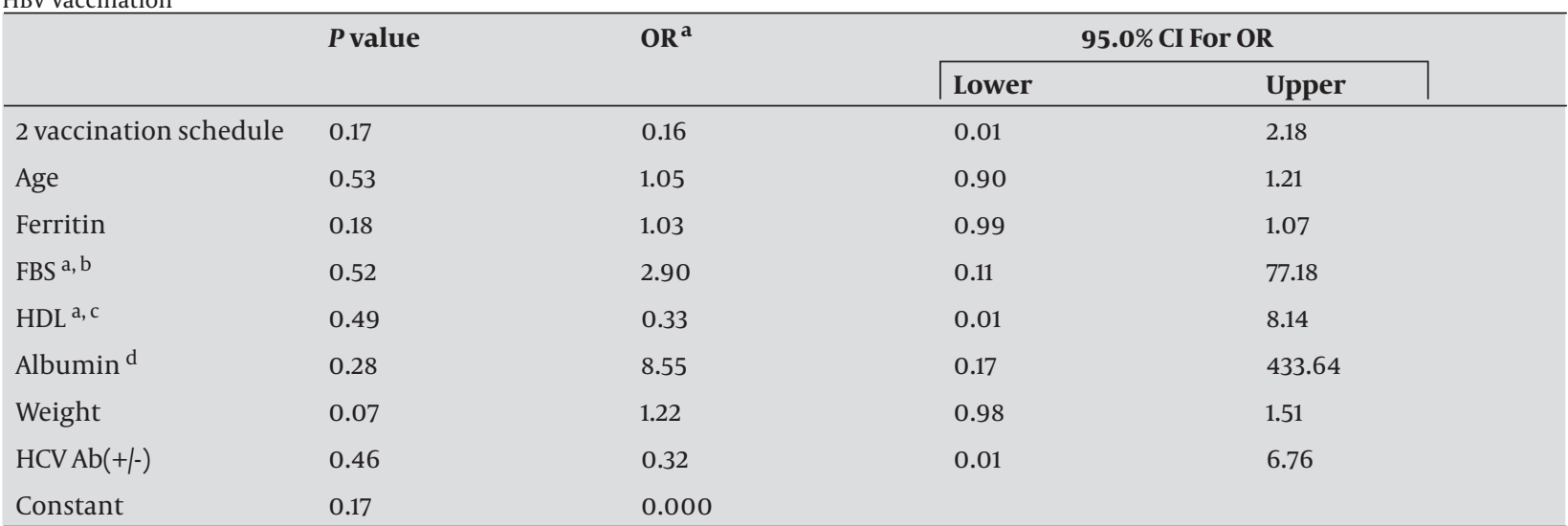

a Abbreviations: FBS, Fasting Blood Sugar; HDL, High-density lipoprotein

${ }^{\mathrm{b}} \mathrm{FBS} \leq 100$ is based

${ }^{\mathrm{c}} \mathrm{HDL} \leq 40$ is based

$\mathrm{d}$ Albumin $\leq 4$ is based 
51 patients at enrolment did not reveal any significant differences between the 2 study groups (Table 1). The etiology of renal disease was as follows: glomerulonephritis $9.8 \%$, diabetes mellitus $13.7 \%$, polycystic kidney disease $11.7 \%$, hypertension $35.3 \%$, diabetes mellitus and hypertension $9.8 \%$, benign prostatic hypertrophy $9.9 \%$, and unknown etiology $9.8 \%$. There were no significant differences in the etiology of renal disease between the 2 groups. Three patients in the 3-dose group (12\%) and 4 in the 4-dose group (15.4\%) had diabetes mellitus $(P=0.52)$. In addition, 3 patients in the 3-dose group were $\mathrm{HCV}$ Ab positive.

The mean HBs Ab level after 4 doses of the $40 \mu \mathrm{g}$ vaccine $(182.2 \pm 286.7)$ was higher than that after 3 doses of the $20 \mu \mathrm{g}$ vaccine (107.6 \pm 192.1$)$, but the difference was not significant $(P=0.3)$. After 4 doses of the $40 \mu \mathrm{g}$ vaccine, the cumulative seroconversion rate (HBs $\mathrm{Ab} \geq 10 \mathrm{mIU} / \mathrm{ml}$ ) was not significantly different $(21 / 26,80.8 \%)$ than that after 3 doses of 20 $\mu \mathrm{g}(23 / 25,92 \%) P=0.41)$. The mean HBs Ab level after 4 doses of $40 \mu \mathrm{g}(182.2 \pm 286.7)$ was significantly higher than that attained after 3 doses of the $40 \mu$ g vaccine $(96.9 \pm 192.1)(P$ $=0.004)$. In addition, after 4 doses of $40 \mu \mathrm{g}(21 / 26,80.8 \%)$, the seroconversion rate was higher than that after 3 doses of $40 \mu \mathrm{g}(20 / 26,77 \%)$. There was no correlation between age and serum HBs Ab level in the 3-dose group; however, there was a negative correlation in the 4-dose group $(\mathrm{r}=-0.58, P=$ 0.002).

\subsection{Multivariable Analysis}

In the logistic regression analysis (Table 2), there was no difference between the group receiving 3 doses of $20 \mu \mathrm{g}$ and those receiving 4 doses of $40 \mu \mathrm{g}$ of $\mathrm{HBV}$ vaccine in terms of predicting the proportion with seroconversion, adjusting for age, ferritin, FBS, HDL, Alb, weight, and HCV Ab.

\section{Discussion}

Patients with renal insufficiency have a suboptimal response to HBV vaccination, and frequent boosters are needed to maintain protection $(23,24)$. We compared $2 \mathrm{HBV}$ vaccination schedules, namely $20 \mu \mathrm{g}$ at 0,1 , and 6 months and $40 \mu$ g at $0,1,2$, and 6 months. There was no significant difference in the seroconversion rate between the $40 \mu \mathrm{g}$ 4-dose vaccination group (21/26, 80.8\%) and the $20 \mu$ 3 3-dose group (23/25, 92\%). These findings support the McNulty et al. study results (22). In that study, 3 doses of $40 \mu \mathrm{g}(67 \%)$ attained equivalent seroconversion to 3 doses of $20 \mu \mathrm{g}$.(57\%) (22). In our study, the mean HBs Ab level after 4 doses of $40 \mu \mathrm{g}(182.2$ $\pm 286.7)$ was significantly higher than that after 3 doses of 40 $\mu \mathrm{g}(96.9 \pm 192.1)(P=0.004)$. In addition, seroconversion was greater after 4 doses of $40 \mu \mathrm{g}(21 / 26,80.8 \%)$ compared with after 3 doses of $40 \mu \mathrm{g}(20 / 26,77 \%)$. As reported in some other studies $(25,26)$, dialysis patients who did not seroconvert after the 3-dose course often did seroconvert after the fourth dose. Agarwal et al. (26) compared $2 \mathrm{HBV} 40 \mu \mathrm{g}$ vaccination schedules among patients with mild, moderate, and severe chronic renal failure (CRF): 0,1, and 2 months (3-dose group) vs. 0,1,2, and 6 months (4-dose group). In the 3-dose group, the seroconversion rate among those with mild, moderate, and severe CRF was $87.5 \%, 66.6 \%$, and $35.7 \%$, respectively, and in 4-dose group it was $100 \%, 77 \%$, and $36.36 \%$. They concluded that patients with CRF should be vaccinated at the very early stage of the disease using $40 \mu \mathrm{g}$ of vaccine, and that 4 doses is better than 3 doses (26).

McNulty et al. showed that the median age of the seroconverter group was about 7.5 years lower than that of the non-seroconverter group; however, this difference was not significant (22). Fabrizi et al. (27) conducted a meta-analysis of 17 clinical trials involving end-stage renal disease patients, and found an association between older age and impaired response to the HBV vaccine. In another study in Iran, higher age ( $>60$ years) was negatively correlated with seroconversion (odds ratio $=0.22 ; P=0.004$ ). (28) In our study, there was no correlation between age and serum HBs $\mathrm{Ab}$ level in the 3-dose group; however, there was a negative correlation in the 4-dose group $(r=-0.58, P=0.002)$. Similar to other reports $(22,29)$, in this study, there was no noticeable association between GFR and seroconversion rate. The sample size was too small to notice a significant difference. A study investigating the effect of renal function on seroconversion rates suggested that CKD patients with higher GFR levels were more likely to respond to vaccination (30). The overall vaccine response rate was $86.27 \%$. This was similar to DaRoza et al.'s study (30). The seroconversion rate in the Hashemi et al. study was 78\%, (lower than the results of our study) (28). Edey et al. (31) in a review article explained that the 3-dose schedule of HBV vaccine in immunocompetent individuals may lead to a 90-95\% seroprotection rate; however, in patients with renal failure, the rates were lower. They suggested that dialysis patients should receive higher vaccine doses such as $40 \mu \mathrm{g}$ at 0,1 , and 6 months, or $40 \mu \mathrm{g}$ at $0,1,2$, and 6 months to improve immune response. In this review, the best reported response rates to these schedules were $<85 \%$ (31). Joukar et al. (32), in a study of hemodialysis patients in Guilan, north of Iran, concluded that despite the low rate of $\mathrm{HBV}$ infection in that region, $\mathrm{HBV}$ vaccination of end-stage renal disease patients before chronic hemodialysis can prevent HBV infection (32).

In our study, seroconversion (HBs $\mathrm{Ab} \geq 10 \mathrm{mIU} / \mathrm{ml}$ ) in the $40 \mu \mathrm{g} 4$ dose group was $80.8 \%$, and in $20 \mu \mathrm{g} 3$ dose group was 92\%, $(P=0.41)$.

The mean antibody titers after three doses of $20 \mu \mathrm{g}$ vaccine (107.6 \pm 192.1$)$, was lower than four doses of $40 \mu \mathrm{g}$ (182.2 \pm 286.7 ), but was not significant.

We hypothesized that four doses of $40 \mu \mathrm{g}$ may be better than three doses of $20 \mu \mathrm{g}$, but we did not find any difference between two methods. These results may be related to small sample size, large standard deviation of HBs Ab levels, and lack of statistical power.

Limitations of the study: The sample size available for this time of study regarding to inclusion and exclusion criteria and time period did not reach to calculated sample size. 


\section{Conclusion}

We found that the 4-dose $40 \mu \mathrm{g}$ HBV vaccine did not lead to significantly greater seroconversion than 3 doses of 20 $\mu \mathrm{g}$. Thus, it is perhaps not necessary to introduce a 4-dose $40 \mu \mathrm{g} \mathrm{HBV}$ vaccination schedule to replace the 3-dose $20 \mu \mathrm{g}$ schedule for predialysis vaccination of patients with stage 3 and 4 CKD. However, further studies with a larger sample size are required.

\section{Acknowledgements}

None declared.

\section{Authors' Contribution}

Authors has been worked equally on this study.

\section{Financial Disclosure}

None declared.

\section{Funding/Support}

All authors disclose that they had no actual or potential conflict of interest including any financial, personal, or other relationships with relevant individuals or organizations within three years of beginning the submitted work that could inappropriately influence, or be perceived to influence, their work.

\section{References}

1. Tang S, Lai KN. Chronic viral hepatitis in hemodialysis patients. Hemodial Int. 2005;9(2):169-79.

2. Recommendation of the Immunization Practices Advisory Committee (ACIP). Inactivated hepatitis B virus vaccine. MMWR Morb Mortal Wkly Rep.1982;31(24):317-22, 27-8.

3. van Dijk PC, Jager KJ, de Charro F, Collart F, Cornet R, Dekker FW, et al. Renal replacement therapy in Europe: the results of a collaborative effort by the ERA-EDTA registry and six national or regional registries. Nephrol Dial Transplant. 2001;16(6):1120-9.

4. Johnson DW, Fleming SJ. The use of vaccines in renal failure. Clin Pharmacokinet. 1992;22(6):434-46.

5. Finelli L, Miller JT, Tokars JI, Alter MJ, Arduino MJ. National surveillance of dialysis-associated diseases in the United States, 2002. Se$\min$ Dial. 2005;18(1):52-61.

6. Infection control requirements for dialysis facilities and clarification regarding guidance on parenteral medication vials. MMWR Morb Mortal Wkly Rep. 2008;57(32):875-6.

7. Peces R, de la Torre M, Alcazar R, Urra JM. Prospective analysis of the factors influencing the antibody response to hepatitis $B$ vaccine in hemodialysis patients. Am J Kidney Dis. 1997;29(2):239-45.

8. Pesanti EL. Immunologic defects and vaccination in patients with chronic renal failure. Infect Dis Clin North Am. 2001;15(3):813-32.

9. Docci D, Cipolloni PA, Mengozzi S, Baldrati L, Capponcini C, Feletti C. Immunogenicity of a recombinant hepatitis B vaccine in hemodialysis patients: a two-year follow-up. Nephron. 1992;61(3):352-3.

10. Mitwalli A. Responsiveness to hepatitis B vaccine in immunocompromised patients by doubling the dose scheduling. Nephron. 1996;73(3):417-20.

11. Fabrizi F, Dixit V, Magnini M, Elli A, Martin P. Meta-analysis: intradermal vs. intramuscular vaccination against hepatitis B virus in patients with chronic kidney disease. Aliment Pharmacol Ther 2006;24(3):497-506.

12. Brodersen HP, Holtkamp W, Larbig D, Beckers B, Thiery J, Lauten- schlager J, et al. Zinc supplementation and hepatitis B vaccination in chronic haemodialysis patients: a multicentre study. Nephrol Dial Transplant.1995;10(9):1780.

13. Argani H, Akhtarishojaie E. Levamizole enhances immune responsiveness to intra-dermal and intra-muscular hepatitis B vaccination in chronic hemodialysis patients. I Immune Based TherVaccines. 2006;4:3.

14. Quiroga JA, Castillo I, Porres JC, Casado S, Saez F, Gracia Martinez M, et al. Recombinant gamma-interferon as adjuvant to hepatitis B vaccine in hemodialysis patients. Hepatology. 1990;12(4 Pt1):661-3.

15. Jungers P, Devillier P, Salomon H, Cerisier JE, Courouce AM. Randomised placebo-controlled trial of recombinant interleukin-2 in chronic uraemic patients who are non-responders to hepatitis B vaccine. Lancet. 1994;344(8926):856-7.

16. Verkade MA, van de Wetering J, Klepper M, Vaessen LM, Weimar W, Betjes MG. Peripheral blood dendritic cells and GM-CSF as an adjuvant for hepatitis B vaccination in hemodialysis patients. Kidney Int. 2004;66(2):614-21.

17. Rangel MC, Coronado VG, Euler GL, Strikas RA. Vaccine recommendations for patients on chronic dialysis. The Advisory Committee on Immunization Practices and the American Academy of Pediatrics. Semin Dial. 2000;13(2):101-7.

18. Chow KM, Law MC, Leung CB, Szeto CC, Li PK. Antibody response to hepatitis B vaccine in end-stage renal disease patients. Nephron Clin Pract. 2006;103(3):C89-93.

19. Dukes CS, Street AC, Starling JF, Hamilton JD. Hepatitis B vaccination and booster in predialysis patients: a 4-year analysis. Vaccine. 1993;11(12):1229-32.

20. Seaworth B, Drucker J, Starling J, Drucker R, Stevens C, Hamilton J. Hepatitis B vaccines in patients with chronic renal failure before dialysis.J Infect Dis. 1988;157(2):332-7.

21. Bel'eed K, Wright M, Eadington D, Farr M, Sellars L. Vaccination against hepatitis $B$ infection in patients with end stage renal disease. Postgrad Med J. 2002;78(923):538-40.

22. McNulty CA, Bowen JK, Williams AJ. Hepatitis B vaccination in predialysis chronic renal failure patients a comparison of two vaccination schedules. Vaccine. 2005;23(32):4142-7.

23. Waite NM, Thomson LG, Goldstein MB. Successful vaccination with intradermal hepatitis B vaccine in hemodialysis patients previously nonresponsive to intramuscular hepatitis B vaccine. J Am Soc Nephrol. 1995;5(11):1930-4.

24. Chang PC, Schrander-van der Meer AM, van Dorp WT, van Leer E. Intracutaneous versus intramuscular hepatitis $B$ vaccination in primary non-responding haemodialysis patients. Nephrol Dial Transplant.1996;11(1):191-3.

25. Rosman AS, Lieber CS. Improving the response to hepatitis B vaccine. Infect Med.1999;16:205-1810.

26. Agarwal SK, Irshad M, Dash SC. Comparison of two schedules of hepatitis B vaccination in patients with mild, moderate and severe renal failure. J Assoc Physicians India. 1999;47(2):183-5.

27. Fabrizi F, Martin P, Dixit V, Bunnapradist S, Dulai G. Meta-analysis the effect of age on immunological response to hepatitis $B$ vaccine in end-stage renal disease. Aliment Pharmacol Ther.2004;20(10):105362.

28. Hashemi B, Mahdavi-Mazdeh M, Abbasi M, Hosseini-Moghaddam $\mathrm{SM}$, Zinat NH, Ahmadi F. Efficacy of HBV vaccination in various stages of chronic kidney disease: is earlier better? Hepat Mon. 2011;11(10):816-20.

29. Fraser GM, Ochana N, Fenyves D, Neumann L, Chazan R, Niv Y, et al. Increasing serum creatinine and age reduce the response to hepatitis B vaccine in renal failure patients.J Hepatol. 1994;21(3):450-4.

30. DaRoza G, Loewen A, Djurdjev O, Love J, Kempston C, Burnett S, et al. Stage of chronic kidney disease predicts seroconversion after hepatitis B immunization: earlier is better. Am J Kidney Dis. 2003;42(6):1184-92.

31. Edey M, Barraclough K, Johnson DW. Review article: Hepatitis B and dialysis. Nephrology (Carlton). 2010;15(2):137-45

32. Joukar F, Besharati S, Mirpour H, Mansour-Ghanaei F. Hepatitis C and hepatitis B seroprevalence and associated risk factors in hemodialysis patients in Guilan province, north of Iran: HCV and HBV seroprevalence in hemodialysis patients. Hepat Mon. 2011;1(3):178-81. 